\title{
Don't Judge a Book by Its Cover
}

\section{To the Editor:}

Although justifiably aggrieved by an inadvertent reissuance of the August 2008 title page of the Journal of Rheumatology affixed to my September 2008 edition, I hope Duncan Gordon and his respected staff realize that our professional esteem for this journal remains firmly intact.

In fact, I suspect this was simply an elegant ploy to force some subscribers to engage beyond their usual summary review of the titles before shelving the issue. This month, we actually had to view the journal articles to discover what had been published. Now, if he can only find a way to get us to read more than just the abstracts.

ANDREW J. HOLMAN, MD, Pacific Rheumatology Research, 4300 Talbot Road South, Suite 101, Renton, Washington 98055, USA;

E-mail: AJHSeattle@aol.com

Editor's note: We regret the inconvenience to Dr. Holman and other readers of our US edition, who were sent a replacement cover with their October issue.

J Rheumatol 2009;36:2; doi:10.3899/jrheum.080968 